\title{
Figuras del espectáculo en la Asamblea: Calidad dela política ecuatoriana
}

\section{Priscila Alejandra Moreno Pazmiño priscila.moreno@estud.usfq.edu.ec}

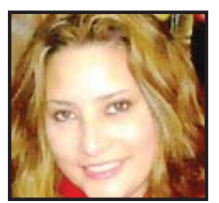

$\mathrm{H}$

ace algunos meses, los jóvenes guayaquileños Daniel Molina y Carlos Serrano, promotores del grupo "Los Indignados", intentaron inscribir a un burro como candidato a la Asamblea Nacional. La noticia fue transmitida, incluso, por varias agencias internacionales. La cuenta de Twitter, @ donburro, en pocas horas llegó a tener más de 5.000 seguidores y hoy supera los 30.000 . [1] Así, Don Burro se ha convertido en un mediador político; en sustituto de los votos nulos o blancos; en emblema de quienes se sienten mal representados y en objeto de crítica humorística a la política.

Este fenómeno surgió como medida de descontento ante la mala calidad de la representación política en el país, suscitado por la inscripción de figuras del espectáculo en las listas para asambleístas nacionales por los diferentes partidos políticos. Para la contienda electoral del 2013, se presentaron los futbolistas Iván Hurtado, Ulises de la Cruz y Agustín Delgado; los cantantes Troy Alvarado, Jaime Enrique Aymara, María de los Ángeles, Gerardo Mejía, Gerardo Morán y Paty Ray; figuras de la pantalla como Carlos José Matamoros y Gabriela Pazmiño; los actores Claudia Camposano, Richard Barker, Mario Cabezas, María Mercedes Pacheco, entre otros. [2]

\section{Antecedentes}

Este fenómeno no es nuevo. Desde hace 14 años, la política se ha convertido en el objetivo que persiguen varios presentadores de televisión, deportistas, cantantes, ex reinas de belleza y actores, ya sea para poten- cializar una carrera artística o simplemente para enfrentarse a nuevos retos. Esta tendencia surgió con el aparecimiento en la arena política de Polo Baquerizo, presentador de TV, en 1998, cuando ganó las elecciones para diputado, auspiciado por Democracia Popular. Ese mismo año, el atleta Rolando Vera se integró al Congreso. En 2002, la cantante Silvana Ibarra triunfó como diputada por el Roldosismo. [3]

Desde entonces, ésta ha sido una estrategia utilizada por los partidos y movimientos políticos para captar el mayor número de votos. Sin embargo, estas figuras no han tenido ninguna trascendencia en la historia política del país, como se evidencia en su escasa participación en la Asamblea. El ex Asambleísta Gerardo Morán lo admitió: "No me siento pleno, en el Pleno; ese no es mi escenario". [3] Aquello es evidente en buena parte de las sesiones, donde pasa inadvertido. [4]

En las Elecciones 2013, reaparecieron varios candidatos sin experticia en el ámbito político, pero cuya imagen es reconocida en el mundo del espectáculo. Incluso Alianza País, que en 2006 rechazó la participación de personajes del espectáculo en los comicios electorales, aprovechó la herramienta en esta ocasión. [5]

Según Verdezoto, el reconocimiento mediático financia por sí solo por lo menos la mitad de lo que le costaría a un político nuevo darse a conocer o ganarse la confianza de los electores. [8] Desde el punto de vista de Oswaldo Moreno, experto en marketing político, el primer paso para ganar una elección es que un alto porcentaje de electores sepa que el candidato existe. Estas candidaturas reflejan la carencia de cuadros de liderazgo dentro de los movimientos del Ecuador. E tener que recurrir a figuras mediáticas destapa la realidad de las agrupaciones: carecen de estructura y militancia. [9]

Así lo reveló Ramiro Gonzáles, director del movimiento AVANZA, tras el escándalo de las firmas falsas: "Con esto de las firmas no nos dieron tiempo a nosotros de armarnos y de estructurar candidaturas en toda la provincia, entonces teníamos que poner gente conocida, pues en apenas 45 días a los partidos nuevos se nos vuelve cuesta arriba posicionar a la gente, entonces sí necesitamos gente conocida, pero que además es gente muy querida, muy reconocida por el pueblo." [10]

\section{El desempeño de las figuras públicas} en la política

El campo político se ha convertido en un continuo espectáculo de masas, en donde no se discuten planes ni programas y mucho menos definiciones doctrinales. Más bien, la acción se centra únicamente en la simpatía del candidato, no en su discurso, sino en su carisma, para atraer votos. Para el analista político Manuel Cedeño, "este tipo de decisiones políticas se deben a la falta de estructuras ... Lo que se busca es conseguir el voto a como dé lugar, sin generar una verdadera propuesta política." [11]

La falta de compromiso de estas figuras en su ámbito político se evidencia en sus faltas a las sesiones legislativas. Según Rosana Alvarado, Asambleísta por Alianza País, las reiteradas inasistencias se dan porque la normativa del Parlamento no las incluye entre las causales de destitución; al contrario,"solo se imponen multas cuando las faltas no han sido justificadas." [11] 
Eva Oviedo ha dicho con respecto a las ausencias de Gerardo Morán, su esposo, que se deben a que él "no ha querido dejar de lado su carrera artística que lleva más de 27 años y es su prioridad". [11] Asimismo, Gabriela Pazmiño, pese a tener una curul desde 2009, continúa con su trabajo en la televisión; hasta hace poco presentaba el programa 'La Guerra de los Sexos'. [12] Esto, a pesar de que el artículo 127 de la Constitución prohíbe a los asambleístas "desempeñar otra función pública o privada incompatibles con su cargo." [13]

\section{El reflejo de la crisis de partidos}

Como resultado de la incursión de figuras públicas en la política, se ha originado un empobrecimiento de la política en general y de la Función Legislativa en particular. Si no poseen conocimientos doctrinarios y políticos, ¿qué debates generarán o sostendrán para fundamentar la creación o modificación de las leyes que normarán la vida de los ecuatorianos? A lo largo de los años, se ha podido apreciar que la función de estos personajes es conformar mayorías parlamentarias que respalden irreflexiblemente las decisiones de los estrategas que los escogen. Así, el pueblo termina por depositar su confianza en ídolos triunfadores en actividades diametralmente diferentes a las que con su sufragio impulsan.

Se ha relegado el valor de la meritocracia y el fortalecimiento de conceptos elementales de competencia y rendimiento. En este sentido, sería más prudente seleccionar a un gran conjunto de profesionales extraordinarios que han sabido sortear los obstáculos de índole económica y social, para alcanzar el éxito con honestidad, capacidad e inteligencia; a aquellos ciudadanos comunes que nunca han necesitado un medio de comunicación para hacer valiosa su existencia, sino que mediante el anonimato han realizado grandes proezas.

Si bien estos personajes de pantalla gozan de los mismos derechos políticos que cualquier ciudadano del país -su derecho a participar de la política

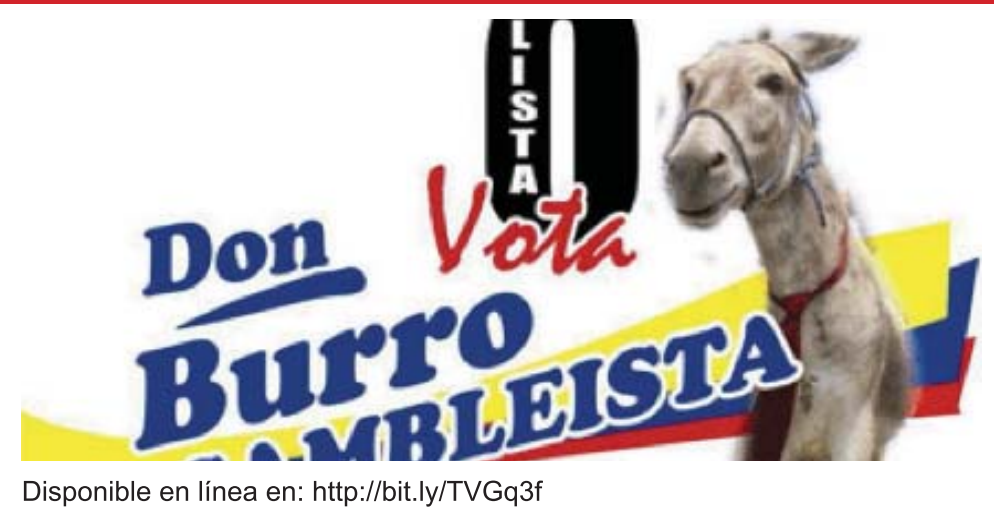

no es cuestionable- lo debatible es el aporte que verdaderamente pueden realizar, en base a su preparación profesional. Son completamente legítimas sus aspiraciones de trabajar "para el pueblo", pero la efectividad de sus acciones se diluye ante la latente incapacidad y poca preparación en relación a sus responsabilidades en la Asamblea. El resultado es el deterioro de la actividad política, en detrimento de las grandes mayorías, plasmándose como una estafa social que no responde a las demandas sociales y populares existentes. Establecer una Asamblea Nacional mediocre y de limitadas ejecutorias es ofender a los representantes elegidos, a los electores y al país.

\section{Fuentes consultadas}

[1] Coello, L. (30 de Noviembre del 2012). Don Burro. El Hoy, 2451, p 13.

[2] Ecuavisa, (30 de Noviembre del 2012). Entre la Farándula y el deporte se pelean las curules para la Asamblea. http://www.ecuavisa.com/noticias/noticias-actualidad/66398-entre-la-farandulay-el-deporte-se-pelean-las-curules-parala-asamblea.html

[3] Verdezoto, N. (21 de Noviembre del 2012). Desde hace 14 años, la farándula y la política se abrazan en elecciones El Comercio, 39233, p.2

[4] Rosero, M. (27 de Julio del 2012). Uno en el Pleno y otro en las Tablas. El Comercio. 3835, p. 4.

[5] Ecuavisa, (30 de Noviembre del 2012). Entre la Farándula y el deporte se pelean las curules para la Asamblea. http://www.ecuavisa.com/noticias/noti- cias-actualidad/66398-entre-la-farandulay-el-deporte-se-pelean-las-curules-parala-asamblea.html

[6] Verdezoto, N. (21 de Noviembre del 2012). Desde hace 14 años, la farándula y la política se abrazan en elecciones. El Comercio, 39233, p.2

[7] El Comercio, (11 de Noviembre del 2012). De la Farándula a la papeleta electoral. http://www.elcomercio.com/politica/ farandula-papeleta-electoral-eleccionesEcuador_0_8075119279.html

[8] Oquendo, M. (15 de Noviembre del 2012. Criticas y Justificaciones a personajes de farándula y fútbol para laAsamblea. http://www.ecuadorinmediato.com/index. php? module=Noticias\&func $=$ news_user_ view \&id=185507\&umt=credticas_y_ justificaciones_a_candidaturas_de_personajes_de_fare-1̄ndula_y_ffatbol_para_ asamblea

[9] Ecuavisa, (30 de Noviembre del 2012). Entre la Farándula y el deporte se pelean las curules para la Asamblea. http://www.ecuavisa.com/noticias/noticias-actualidad/66398-entre-la-farandulay-el-deporte-se-pelean-las-curules-parala-asamblea.html

[10] Mendoza, R. (22 de Agosto del 2010). Asamblea $\$ 180$ por faltas sin justificar. El hoy.28174, p.9

[11] Alvear, J. (6 de Septiembre del 2010). Gabriela Pazmiño tiene su "curul" en la pantalla chica. El Comercio, 39341, p.12

[12] El Comercio (22 de Noviembre del 2012). La política seduce a ex figuras del deporte desde hace 24 años.39234. p, 2.

[13] El Comercio, (11 de Noviembre del 2012). De la Farándula a la papeleta electoral. http://www.elcomercio.com/politica/ farandula-papeleta-electoral-eleccionesEcuador 0 8075119279.html 